\title{
Development of new NLO borate crystals
}

\author{
Y MORI* and T SASAKI \\ Department of Electrical Engineering, Faculty of Engineering, Osaka University, 2-1 Yamadaoka, Suita, \\ Osaka 565-0871, Japan
}

\begin{abstract}
Recently new borate crystals, $\mathrm{CsLiB}_{6} \mathrm{O}_{10}(\mathrm{CLBO}), \mathrm{YCa}_{4} \mathrm{O}\left(\mathrm{BO}_{3}\right)_{3}(\mathrm{YCOB})$ and $\mathrm{Gd}_{x} \mathrm{Y}_{1-x} \mathrm{Ca}_{4} \mathrm{O}\left(\mathrm{BO}_{3}\right)_{3}$ $\left(\mathrm{Gd}_{x} \mathrm{Y}_{1-x} \mathrm{COB}\right)$ have been developed by the present authors. Here, the growth and nonlinear optical properties of CLBO, YCOB and $\mathrm{Gd}_{x} \mathrm{Y}_{1-x} \mathrm{COB}$ crystals are revlewed and their properties are discussed in relation to those of other nonlinear optical crystals, such as $\beta-\mathrm{BaB}_{2} \mathrm{O}_{4}(\mathrm{BBO})$, and $\mathrm{LiB}_{3} \mathrm{O}_{5}(\mathrm{LBO})$.
\end{abstract}

Keywords. Nonlinear optical material; frequency conversion; ultraviolet generation; solid-state lasers; CLBO; noncritically phase-matching; YCOB; GdYCOB.

\section{Introduction}

Many researchers have devoted their efforts to the development of ultraviolet (UV) lasers for industrial and medical applications. The frequency conversion technique of solid state laser radiation in nonlinear optical (NLO) crystals is an effective method for obtaining UV radiation with high beam quality and stability. Borate series, such as $\beta-\mathrm{BaB}_{2} \mathrm{O}_{4}(\mathrm{BBO}) ; \mathrm{LiB}_{3} \mathrm{O}_{5}(\mathrm{LBO})$ and $\mathrm{CsB}_{3} \mathrm{O}_{5}(\mathrm{CBO})$ have been searched as UV NLO crystals (Chen et al 1984, 1989; Wu et al 1993). Recently other new borate crystals, $\mathrm{CsLiB}_{6} \mathrm{O}_{10}$ (CLBO), $\mathrm{YCa}_{4} \mathrm{O}\left(\mathrm{BO}_{3}\right)_{3}(\mathrm{YCOB})$ and $\mathrm{Gd}_{x} \mathrm{Y}_{1-x} \mathrm{Ca}_{4} \mathrm{O}\left(\mathrm{BO}_{3}\right)_{3},\left(\mathrm{Gd}_{x} \mathrm{Y}_{1-x} \mathrm{COB}\right)$ have been discovered and developed by the present authors (Mori et al 1995a; Iwai et al 1997; Yoshimura et al 1998). CLBO crystals can generate the fourth and fifth harmonic of a Nd: YAG laser radiation due to their relatively large birefringence. YCOB is phase-matchable for the third harmonic generation of a Nd: YAG laser. We also confirmed that $\mathrm{Gd}_{0.28} \mathrm{Y}_{0.72} \mathrm{COB}$ makes possible the generation of the $(\theta, \phi)=\left(90^{\circ}, 90^{\circ}\right)$ phase-matched third harmonic of $1064 \mathrm{~nm}$ light. Here, the growth, NLO and frequency conversion properties of $\mathrm{CLBO}, \mathrm{YCOB}$ and $\mathrm{Gd}_{x} \mathrm{Y}_{1-x} \mathrm{COB}$ crystals are reviewed and their properties are discussed in relation to those of other nonlinear optical crystals, such as BBO and LBO.

\section{Borate crystals}

\subsection{CLBO crystals}

CLBO has a tetragonal structure with a space group of I42d (\#122) and cell dimensions of $a=10.494(1)$ and $c=8.939$ (2) for $Z=4$ (Sasaki et al 1995). The structure comprises isolated Cs cations and network of chains

\footnotetext{
*Author for correspondence
}

formed from $\mathrm{B}_{3} \mathrm{O}_{7}$ groups and $\mathrm{Li}$ cations. It consists of a six-membered ring, where two of the boron atoms are three-fold coordinated and the third boron atom in the ring is four-fold coordinated by oxygen atoms. The borate network of CLBO surrounds eight-coordinate Cs atoms and four-coordinate $\mathrm{Li}$ atoms.

The pseudo binary $\left(\mathrm{Cs}_{2} \mathrm{O}+3 \mathrm{~B}_{2} \mathrm{O}_{3}\right)-\left(\mathrm{Li}_{2} \mathrm{O}+3 \mathrm{~B}_{2} \mathrm{O}_{3}\right)$ and $\left(\mathrm{Cs}_{2} \mathrm{O}+\mathrm{Li}_{2} \mathrm{O}\right)-\left(2 \mathrm{~B}_{2} \mathrm{O}_{3}\right)$ phase diagrams were investigated in the ternary $\mathrm{Cs}_{2} \mathrm{O}-\mathrm{Li}_{2} \mathrm{O}-3 \mathrm{~B}_{2} \mathrm{O}_{3}$ system using differential temperature analysis and $\mathrm{X}$-ray diffractometer as shown in figures $1 \mathrm{a}$ and $\mathrm{b}$ (Mori et al 1995b). Figure 1 shows stoichiometric congruent point at $848^{\circ} \mathrm{C}$, meaning that it is easy to grow CLBO crystal compared to BBO and LBO. Phase diagrams show that CLBO crystals can be grown from fluxes that are either poor or rich in $\mathrm{B}_{2} \mathrm{O}_{3}$. This is an advantage for flux growth of CLBO compared with that of LBO, which grows only from a flux rich in $\mathrm{B}_{2} \mathrm{O}_{3}$. This is because crystal growth from a flux rich in $\mathrm{B}_{2} \mathrm{O}_{3}$ is often difficult due to the high viscosity. Therefore, the flux poor in $\mathrm{B}_{2} \mathrm{O}_{3}$ was used to grow large crystals. The starting charges were prepared from a mixture of $\mathrm{Cs}_{2} \mathrm{CO}_{3}, \mathrm{Li}_{2} \mathrm{CO}_{3}$, and $\mathrm{B}_{2} \mathrm{O}_{3}$ with ratio of $1: 1: 5.5\left(73.3 \% \quad \mathrm{~B}_{2} \mathrm{O}_{3}\right)$. The measured saturation temperature was $845^{\circ} \mathrm{C}$. The growth temperature was varied from $845^{\circ} \mathrm{C}$ to $843.5^{\circ} \mathrm{C}$ with a temperature decrease of $\sim 0.1^{\circ} \mathrm{C} /$ day. The growing crystal was rotated at a rate of $15 \mathrm{rpm}$ with inverting the rotation direction every 3 min. Figure 2 shows a CLBO crystal with dimensions of $14 \times 11 \times 11 \mathrm{~cm}^{3}$ grown under this condition for three weeks (Mori et al 1995a). This crystal exhibited well distinguishable facets.

The transmission range of CLBO crystal was from $180 \mathrm{~nm}$ to $2750 \mathrm{~nm}$. The absorption edge of CLBO at $180 \mathrm{~nm}$ is shorter than the reported value of BBO $(189 \mathrm{~nm})$ but longer than those reported for LBO $(160 \mathrm{~nm})$. The refractive indices were determined by the method of minimum deviation. The Sellmeier equations predict 
the limits of types I and II PM wavelengths to be 472 and $640 \mathrm{~nm}$, respectively. The Sellmeier equations also predict the fifth-harmonic generation (5HG) of Nd: YAG laser radiation in CLBO crystal by mixing the first and fourth harmonics radiations (Mori et al 1995c). Table 1 shows values of angular, spectral and temperature bandwidths and walk-off angle for various frequency conversion process in the CLBO and BBO for $266 \mathrm{~nm}$ and $213 \mathrm{~nm}$ generations. Despite the smaller nonlinear coefficient, CLBO possesses smaller walk-off angle, and larger angular and spectral bandwidths compared to BBO. The temperature acceptance of CLBO is larger than that of BBO. As shown in table 1, CLBO exhibits better NLO properties compared to BBO and this is supported by the following experimental results as well.

High average power all solid state UV laser was obtained at a pulse rate of $100 \mathrm{~Hz}$ and $1000 \mathrm{~Hz}$ by CLBO. In case of $100 \mathrm{~Hz}$ pulse rate, $9.7 \mathrm{~W}$ of $266 \mathrm{~nm}$ and $4.0 \mathrm{~W}$ of $213 \mathrm{~nm}$ were detected. The conversion efficiency from $1064 \mathrm{~nm}$ to $213 \mathrm{~nm}$ was $11.8 \%$ (Yap et al 1996). In case of $1000 \mathrm{~Hz}$ pulse rate, $2.5 \mathrm{~W}$ of $266 \mathrm{~nm}$ and $1.0 \mathrm{~W}$ of $213 \mathrm{~nm}$ were obtained from fundamental of $8.8 \mathrm{~W}$, which correspond to an efficiency of
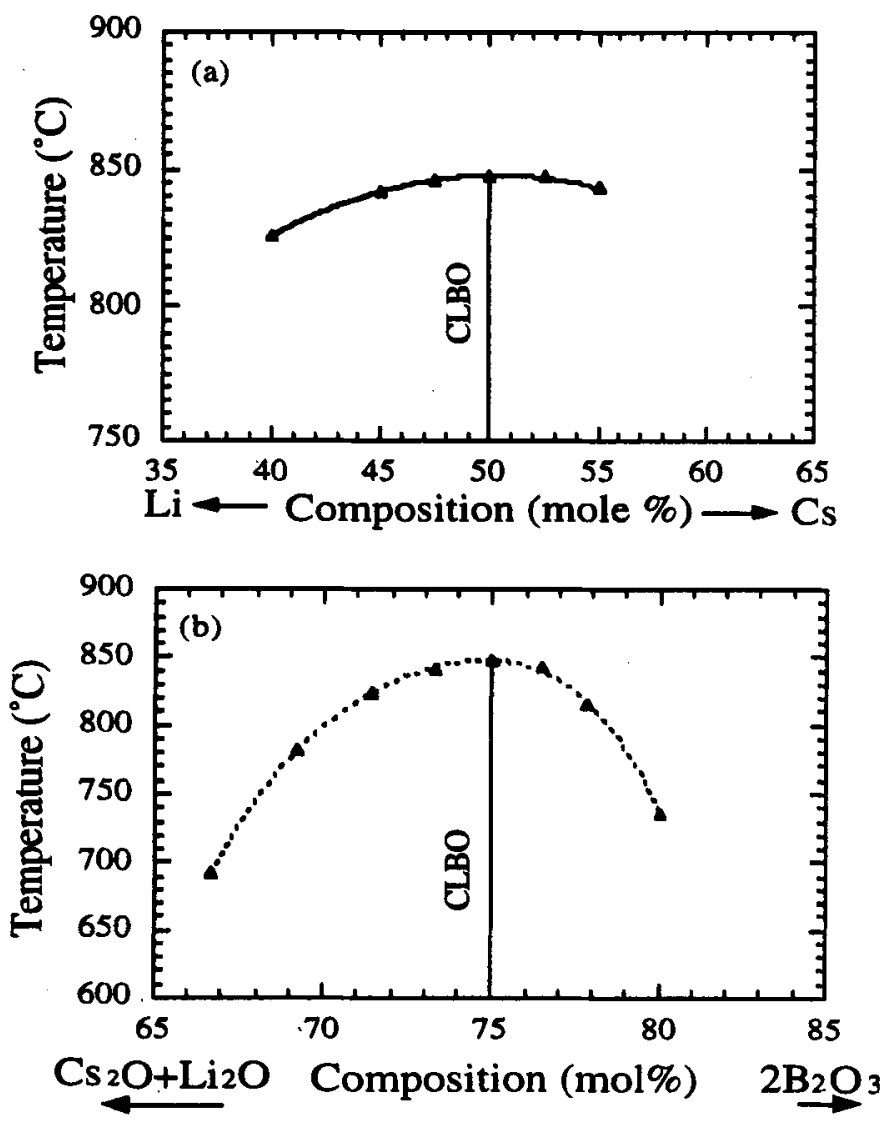

Figure 1. The pseudo binary $\left(\mathrm{Cs}_{2} \mathrm{O}+3 \mathrm{~B}_{2} \mathrm{O}_{3}\right)-\left(\mathrm{Li}_{2} \mathrm{O}+3 \mathrm{~B}_{2} \mathrm{O}_{3}\right)$ and $\left(\mathrm{Cs}_{2} \mathrm{O}+\mathrm{Li}_{2} \mathrm{O}\right)-\left(2 \mathrm{~B}_{2} \mathrm{O}_{3}\right)$ phase diagrams investigated in the temary $\mathrm{Cs}_{2} \mathrm{O}-\mathrm{Li}_{2} \mathrm{O}-\mathrm{B}_{2} \mathrm{O}_{3}$ system.
$11.4 \%$ from $1064 \mathrm{~nm}$ to $213 \mathrm{~nm}$ (Stamm et al 1997). Moderate birefringence made CLBO possess a smaller walk-off angle so as to achieve better spatial overlapping of the mixing beams compared to BBO. Thus, higher conversion efficiency and better beam pattern of harmonics generation can be achieved. Its relatively large angular, spectral and temperature acceptance bandwidths at $532 \mathrm{~nm}$ have favoured CLBO for stable $266 \mathrm{~nm}$ generation of high power Nd:YAG laser. All these properties and its shorter absorption edge down to $180 \mathrm{~nm}$ eventually lead to a high conversion efficiency and stable $213 \mathrm{~nm}$ generation.

\section{YCOB and $\mathrm{Gd}_{x} \mathrm{Y}_{1-x} \mathrm{COB}$ crystals}

Khamaganova et al (1991) grew a new borate crystal of $\mathrm{Ca}_{8} \mathrm{Sm}_{2} \mathrm{O}_{2}\left(\mathrm{BO}_{3}\right)_{6}$ from a PbO flux. Norrestam et al (1992) succeeded in synthesizing a borate series of $\mathrm{Ca}_{4} \mathrm{RO}\left(\mathrm{BO}_{3}\right)_{3}$, where $\mathrm{R}^{3+}=\mathrm{La}, \mathrm{Nd}, \mathrm{Sm}, \mathrm{Gd}, \mathrm{Er}$ and $\mathrm{Y}$. Following these developments, Aka et al (1996a, b) reported the crystal growth and nonlinear optical properties of $\mathrm{GdCa}_{4} \mathrm{O}\left(\mathrm{BO}_{3}\right)_{3}(\mathrm{GdCOB})$ as a new NLO crystal. This crystal is an excellent candidate for practical NLO devices, because it is nonhygroscopic and chemically stable with good mechanical properties, allowing easy polishing. Although they have mentioned an isomorph $\mathrm{Ca}_{4} \mathrm{O}\left(\mathrm{BO}_{3}\right)_{3}$ (YCOB) briefly, its detailed characteristics have not been shown yet.

In previous work (Iwai et al 1997; Yoshimura et al 1998), we found that the substitution of a smaller radius cation such as $\mathrm{Y}^{3+}(0.900 \AA)$ (Shannon 1976) for $\mathrm{Gd}^{3+}$ $(0.938 \AA)$ on the trivalent rare earth site leads to larger optical birefringence. As a result, the wavelength limit of type I second harmonic generation (SHG) can be shortened to $720 \mathrm{~nm}$. In addition, YCOB is phasematchable for the third harmonic generation (THG) of

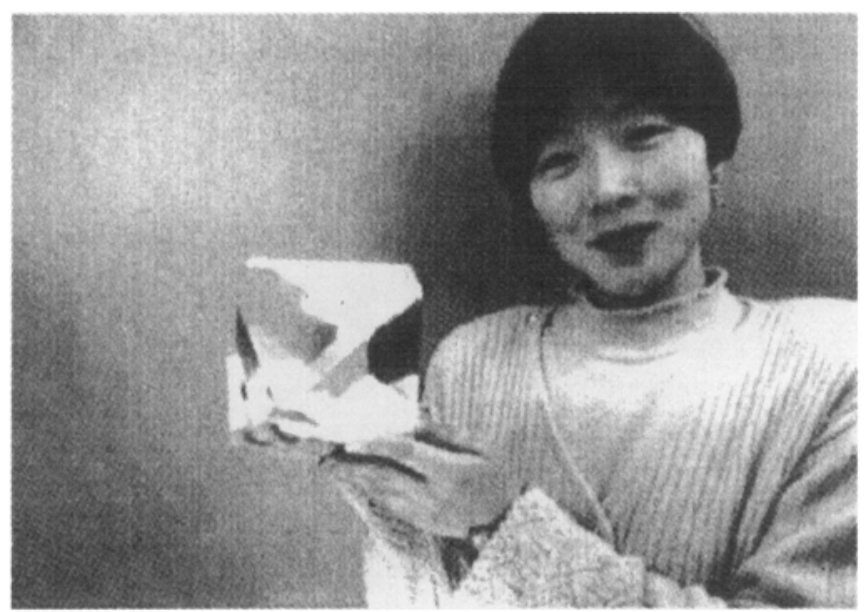

Figure 2. Photograph of large CLBO crystal with dimensions of $14 \times 11 \times 11 \mathrm{~cm}^{3}$. 
Table 1. NLO properties of CLBO and BBO for $266 \mathrm{~nm}$ and $213 \mathrm{~nm}$ generations.

\begin{tabular}{llcccccc}
\hline $\begin{array}{l}\text { Wavelength } \\
(\mathrm{nm})\end{array}$ & Crystal & $\begin{array}{c}\text { PM } \\
\text { angle } \\
(\mathrm{deg} .)\end{array}$ & $\begin{array}{c}d_{\text {eff }} \\
(\mathrm{pm} / \mathrm{V})\end{array}$ & $\begin{array}{c}\text { Angular } \\
\text { bandwidth } \\
(\mathrm{mrad} \mathrm{cm})\end{array}$ & $\begin{array}{c}\text { Spectral } \\
\text { bandwidth } \\
(\mathrm{nm} \mathrm{cm})\end{array}$ & $\begin{array}{c}\text { Temperature } \\
\text { bandwidth } \\
\left({ }^{\circ} \mathrm{C} \mathrm{cm}\right)\end{array}$ & $\begin{array}{c}\text { Walk-off } \\
\text { angle } \\
(\mathrm{deg})\end{array}$ \\
\hline $532+532=266$ & CLBO & 62 & 0.85 & 0.49 & 0.13 & 8.3 & 1.83 \\
& BBO & 48 & 1.32 & 0.17 & 0.07 & 4.5 & 4.80 \\
$1064+266=213$ & CLBO & 67 & 0.88 & 0.42 & 0.16 & 4.6 & 1.69 \\
& BBO & 51 & 1.26 & 0.11 & 0.08 & 3.1 & 5.34 \\
\hline
\end{tabular}

a Nd: YAG laser by type I mixing between 1064 and $532 \mathrm{~nm}$, whereas GdCOB is not. Here, we present the crystal growth and NLO properties of $\mathrm{YCa}_{4} \mathrm{O}\left(\mathrm{BO}_{3}\right)_{3}$ (YCOB) compared with those of $\mathrm{GdCOB}$. Furthermore, we confirmed that a substitutional solid solution of $\mathrm{Gd}_{x} \mathrm{Y}_{1-x} \mathrm{Ca}_{4} \mathrm{O}\left(\mathrm{BO}_{3}\right)_{3} \quad\left(\mathrm{Gd}_{x} \mathrm{Y}_{1-x} \mathrm{COB}\right)$ has compositional uniformity along the growth direction. We also report the THG phase-matching properties of $\mathrm{Gd}_{x} \mathrm{Y}_{1-x} \mathrm{Ca}_{4} \mathrm{O}\left(\mathrm{BO}_{3}\right)_{3}\left(\mathrm{Gd}_{x} \mathrm{Y}_{1-x} \mathrm{COB}\right)$ crystal in various compositions to achieve a noncritically phase matching (NCPM) condition at room temperature. For frequency conversion applications, the NCPM condition is advantageous due to its large angular acceptance and the elimination of walk-off between fundamental and harmonic lights.

Single crystals of $\mathrm{YCOB}$ and $\mathrm{Gd}_{x} \mathrm{Y}_{1-x} \mathrm{COB}$, up to $1 \mathrm{~cm}$ in diameter by $5 \mathrm{~cm}$ in length, were grown by the conventional Czochralski technique. YCOB was grown in an $\mathrm{Ar}$ atmosphere at $1510^{\circ} \mathrm{C}$, which is about $30^{\circ} \mathrm{C}$ higher than the temperature used for growing GdCOB; the increase of $\mathrm{Gd}$ concentration in $\mathrm{Gd}_{x} \mathrm{Y}_{1-x} \mathrm{COB}$ lowers the growth temperature. The typical pull and rotation were $3 \mathrm{~mm} / \mathrm{h}$ and $20 \mathrm{rpm}$, respectively. Although numerous cracks tended to form during the cooling process, the $\langle 010\rangle$ oriented seed prevented the cracks. Figure 3 shows the typical $\mathrm{Gd}_{x} \mathrm{Y}_{1-x} \mathrm{COB}$ crystal.

We examined the compositional uniformity along the growth direction of $\mathrm{Gd}_{x} \mathrm{Y}_{1-x} \mathrm{COB}$ crystals, sampling at the positions of 5,20 and $35 \mathrm{~mm}$ from the seed crystal, by means of inductively coupled plasma (ICP) atomic emission spectroscopy. Two samples of $\mathrm{Gd}_{x} \mathrm{Y}_{1-x} \mathrm{COB}$ $(x=0.13,0.48)$ single crystals were used. It was found that the crystals showed a high uniformity of composition with 13 and $48 \%$ of $\mathrm{Gd}$, respectively, along the growth direction as shown in figure 4 . We also measured the ratios of lattice constants $(a / c, a / b)$ in $\mathrm{Gd}_{x} \mathrm{Y}_{1-x} \mathrm{COB}$ $(x=0,0.48,1)$ crystals by means of a four-circle X-ray diffractometer as shown in figure 5. The ratios of lattice constants $a / c$ and $a / b$ in $\mathrm{Gd}_{x} \mathrm{Y}_{1-x} \mathrm{COB}$ linearly change as the compositional parameter $x$ increases. This result implies that $\mathrm{Gd}_{x} \mathrm{Y}_{1-x} \mathrm{COB}$ is a substitutional solid solution and that it is possible to vary the refractive indices continuously.

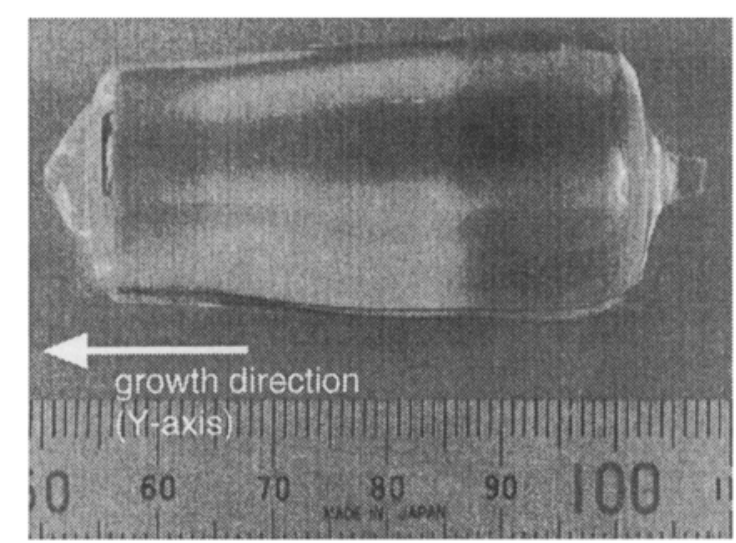

Figure 3. Typical $\mathrm{Gd}_{x} \mathrm{Y}_{1-x} \mathrm{COB}(x=0.24)$ single crystal grown by the Czochralski method.

The ranges of transparency for YCOB and $\mathrm{Gd}_{0.48} \mathrm{Y}_{0.52} \mathrm{COB}$ were determined in samples of 2 and $5 \mathrm{~mm}$ thickness. The transmission ranges of these samples are from $250 \mathrm{~nm}$ to $2500 \mathrm{~nm}$. The absorption edges are $210 \mathrm{~nm}$. For Gd-contained crystals, six sharp absorption lines due to $\mathrm{Gd}^{3+}$ ions were observed in the range $240-320 \mathrm{~nm}$, whereas no absorption was observed in YCOB.

$\mathrm{Gd}_{x} \mathrm{Y}_{1-x} \mathrm{COB}$ is a biaxial crystal and belongs to the monoclinic system with $\mathrm{Cm}$ space symmetry. The dielectric axes $(X Y Z)$ are labelled by the refractive index associated with them, $n_{x}<n_{y}<n_{z}$. The $Y$ axis is parallel to the crystallographic $b$ axis. The magnitude of birefringence $n_{z}-n_{x}$ relates to the phase-matching conditions for frequency conversion. The three principal refractive indices of $\mathrm{GdCOB}$ and YCOB were measured at wavelengths between 270 and $1200 \mathrm{~nm}$ by the method of minimum deviation (Iwai et al 1997; Yoshimura et al 1998). The shortest type I SHG wavelength calculated from the Sellmeier equations is $720 \mathrm{~nm}$. This is shorter than that for GdCOB $(840 \mathrm{~nm})$, because birefringence of $\mathrm{YCOB}$ is greater than that of $\mathrm{GdCOB}$. For instance, the magnitudes of birefringence $n_{z}-n_{x}$ at $1064 \mathrm{~nm}$ for YCOB and GdCOB are 0.041 and 0.033 , respectively. In addition to SHG of a Nd: YAG laser, THG can be 
realized in YCOB by type I mixing between 1064 and $532 \mathrm{~nm}$, whereas in GdCOB it cannot.

$\mathrm{YCOB}$ and $\mathrm{Gd}_{x} \mathrm{Y}_{1-\mathrm{x}} \mathrm{COB}$ crystals, typically $9 \mathrm{~mm}$ long in various compositions, were cut at the $Y$ axis or phasematching direction for THG. The faces were polished and uncoated. The measurements for phase-matching properties were performed by using a Q-switched Nd:YAG laser (Spectra-Physics GCR190) which is operated at a repetition rate of $10 \mathrm{~Hz}$. The type I phasematching angles for THG $(1064+532 \rightarrow 355 \mathrm{~nm})$ in YCOB were experimentally determined to be $(\theta, \phi)=\left(90^{\circ}\right.$, $\left.73.2^{\circ}\right)$ and $\left(58.7^{\circ}, 90^{\circ}\right)$ in the $X Y$ and $Y Z$ planes, respectively. In general, as the birefringence of biaxial crystal decreases, the phase-matching angles in the $X Y$ and $Y Z$ planes change toward $(\theta, \phi)=\left(90^{\circ}, 90^{\circ}\right)$. Partial substitution of $\mathrm{Gd}$ for $\mathrm{Y}$ in $\mathrm{YCOB}$ crystals makes the birefringence small, therefore we expect to achieve NCPM THG along the $Y$ axis by adjusting the Gd-concentration.

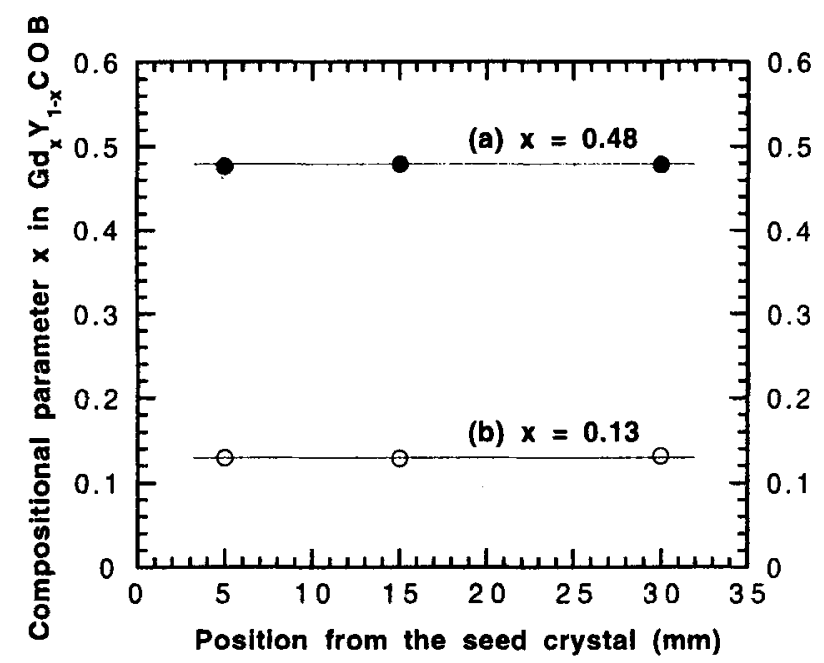

Figure 4. Uniformity of crystal composition of (a) $\mathrm{Gd}_{0.48} \mathrm{Y}_{0.52} \mathrm{COB}$ and (b) $\mathrm{Gd}_{0.13} \mathrm{Y}_{0.87} \mathrm{COB}$ along the growth direction.

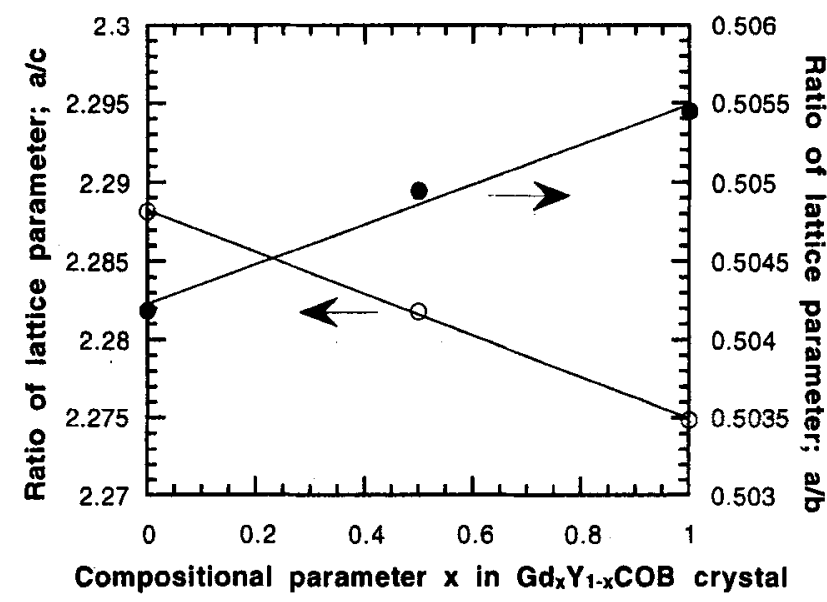

Figure 5. The ratios of lattice constants $(a / c, a / b)$ in $\mathrm{Gd}_{x} \mathrm{Y}_{1-x} \mathrm{COB}(x=0,0.48,1)$ crystals.
We examined the phase-matching angles on the principal planes $(X Y, Y Z)$ for various $\mathrm{Gd}_{x} \mathrm{Y}_{1-x} \mathrm{COB}$ compounds. The experiments were carried out at room temperature. Figure 6 represents the phase-matching angles for THG as a function of the compositional parameter $x$ in $\mathrm{Gd}_{x} \mathrm{Y}_{1-x} \mathrm{COB}$ crystals. For curve a, the wave vector $\mathbf{k}$ is in the $X Y$ plane and the phase-matching angle is $\phi$ from the $X$ axis. Similarly, for curve $b$ the phase-matching angle is $\theta$ from the $Z$ axis in the $Y Z$ plane. The phase-matching angles gradually changed to $90^{\circ}$ due to an increase of $x$ in $\mathrm{Gd}_{x} \mathrm{Y}_{1-x} \mathrm{COB}$. At $x=0.24$ the phase-matching angle reaches $(\theta, \phi)=\left(90^{\circ}, 90^{\circ}\right)$, which is type I noncritical phase-matching at room temperature. For $x>0.28$, the third harmonic lights were also generated at $(\theta, \phi)=\left(90^{\circ}, 90^{\circ}\right)$, although the intensity gradually declined due to an increase of $x . \mathrm{Gd}_{0.29} \mathrm{Y}_{0.71} \mathrm{COB}$ crystal generated detectable third harmonic lights, this means that the compositional parameter $x$ is not critical for NCPM THG.

We measured the phase-matching properties for THG in $9.3 \mathrm{~mm}$ long $\mathrm{Gd}_{0.28} \mathrm{Y}_{0.72} \mathrm{COB}$ and $9.6 \mathrm{~mm}$ long $\mathrm{YCOB}$ crystals. The effective nonlinear coefficients $d_{\mathrm{efr}}$ were calculated from the third harmonic energy and the refractive indices by comparison with those of $\mathrm{LBO}$. A type I LBO $(X Y)$ with a length of $7.5 \mathrm{~mm}$ $\left(d_{\text {eff }}=0.68 \mathrm{pm} / \mathrm{V}\right)$ was used as a reference (Roberts 1992; Kato 1994). The ambiguity in the refractive indices of $\mathrm{Gd}_{0.28} \mathrm{Y}_{0.72} \mathrm{COB}$ gives no significant error in the value of $d_{\text {effl }}$. Therefore, the refractive indices were interpolated between the indices of GdCOB and YCOB. It was found that the $d_{\text {eff }}$ of $\mathrm{Gd}_{0.28} \mathrm{Y}_{0.72} \mathrm{COB}$ is $0.55 \mathrm{pm} / \mathrm{V}$, which is slightly larger than that for YCOB $(X Y)$ at $0.52 \mathrm{pm} / \mathrm{V}$.

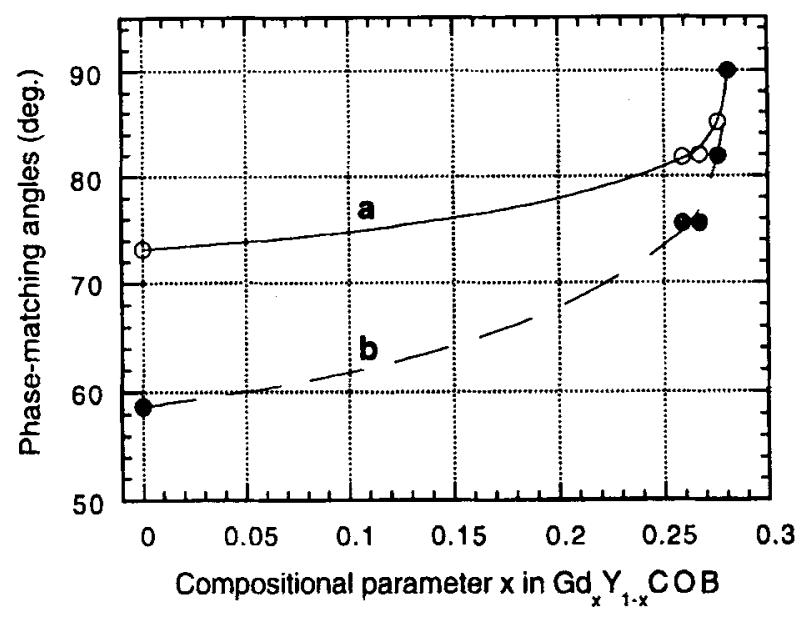

Figure 6. Phase-matching angles for THG in $\mathrm{Gd}_{x} \mathrm{Y}_{1-x} \mathrm{COB}$ in the $X Y$ and $Y Z$ planes of $\mathrm{Gd}_{x} \mathrm{Y}_{1-x} \mathrm{COB}$ as a function of the compositional parameter $x$. For curve a the wave vector $\mathbf{k}$ is in the $X Y$ plane and the phase-matching angle is $\phi$ from the $X$ axis. Similarly, for curve $\mathbf{b}$ the phase-matching angle is $\theta$ from the $Z$ axis in the $Y Z$ plane. 
Table 2. Phase-matching properties for type I THG $(1064+532 \rightarrow 355 \mathrm{~nm})$ of $\mathrm{Gd}_{x} \mathrm{Y}_{\mathbf{1}-x} \mathrm{COB}$.

\begin{tabular}{|c|c|c|c|c|c|}
\hline & \multirow{2}{*}{$\underset{(\mathrm{pm} / \mathrm{V})}{d_{\mathrm{eff}}}$} & \multicolumn{2}{|c|}{$\begin{array}{l}\text { External angular acceptance } \\
\text { bandwidth }(\operatorname{mrad} \mathrm{cm})\end{array}$} & \multirow{2}{*}{$\begin{array}{c}\text { Temperature } \\
\text { bandwidth } \\
\left({ }^{\circ} \mathrm{C} \mathrm{cm}\right)\end{array}$} & \multirow{2}{*}{$\begin{array}{c}\text { Walk-off } \\
\text { angle } \\
\text { (mrad) }\end{array}$} \\
\hline & & $\Delta \theta_{1}$ & $\Delta \phi 1$ & & \\
\hline YCOB $(X Y)$ & 0.52 & - & $3 \cdot 2$ & 9.7 & 8.5 \\
\hline YCOB $(Y Z)$ & 0.43 & 5.6 & - & $8 \cdot 5$ & 4.7 \\
\hline GdYCOB & 0.55 & $\operatorname{mrad}_{\mathrm{cm}^{1 / 2}}^{114}$ & $\begin{array}{c}65.6 \\
\mathrm{mrad} \mathrm{cm}^{1 / 2}\end{array}$ & 6.6 & 0 \\
\hline
\end{tabular}

The $d_{\text {eff }}$ of monoclinic crystals with $C m$ space symmetry are given by

$$
\begin{aligned}
& \left.d_{\text {eff }} \text { (type I, } X Y\right)=\mathrm{d}_{13} \sin \phi, \\
& \left.d_{\text {eff }} \text { (type I, } Y Z\right)=d_{12} \sin ^{2} \theta+d_{13} \cos ^{2} \theta .
\end{aligned}
$$

Hence the difference in $d_{\text {eff }}$ between YCOB $\left(\phi=73 \cdot 2^{\circ}\right.$; $X Y$ ) and $\mathrm{Gd}_{0.24} \mathrm{Y}_{0.76} \mathrm{COB}$ seems to be caused by the term of $\sin \phi$.

The acceptance angles $\Delta \theta$ and $\Delta \phi$ of $\mathrm{Gd}_{0 \cdot 24} \mathrm{Y}_{0.76} \mathrm{COB}$ were measured by rotating the crystal about the $X$ axis in the $Y-Z$ plane ( $\theta$ direction) and about the $Z$ axis in the $X-Y$ plane ( $\phi$ direction). The FWHM acceptance angles (external) were found to be 33 and $9.7 \mathrm{mrad}$ for the rotation of the $\theta$ and $\phi$ directions, respectively. These values correspond to angular acceptance bandwidths of $\Delta \theta 1^{1 / 2}=34$ and $\Delta \phi 1^{1 / 2}=9 \cdot 3 \mathrm{mrad}(\mathrm{cm})^{1 / 2}$. The temperature tuning curve for THG in $\mathrm{Gd}_{0.24} \mathrm{Y}_{0.76} \mathrm{COB}$ was also measured. The FWHM value phase-matched at $28^{\circ} \mathrm{C}$ is $10.4^{\circ} \mathrm{C}$, corresponding to the temperature bandwidth $\Delta T 1$ of $9.7^{\circ} \mathrm{C} \mathrm{cm}$. Table 2 shows the phase-matching properties for THG of $\mathrm{Gd}_{x} \mathrm{Y}_{1-x} \mathrm{COB}$. The walk-off angles of YCOB are calculated values. The walk-off angle of $\mathrm{Gd}_{0.28} \mathrm{Y}_{0.72} \mathrm{COB}$ is an estimated value. We have improved the angular properties for THG by the substitution of $\mathrm{Gd}$ for $\mathrm{Y}$ in YCOB. These results suggest that $\mathrm{Gd}_{0.28} \mathrm{Y}_{0.72} \mathrm{COB}$ is suitable for THG and that a longer crystal can be utilized for higher frequency conversion efficiency.

\section{Conclusions}

The NLO crystals, CLBO, YCOB and $\mathrm{Gd}_{x} \mathrm{Y}_{1-x} \mathrm{COB}$ have been reviewed. CLBO showed the ease in growth and excellent NLO properties for 4 and 5 harmonics generations. $\mathrm{YCOB}$ and $\mathrm{Gd}_{x} \mathrm{Y}_{1-x} \mathrm{COB}$ crystals also showed the ease in growth without cracks and bubbles by the Czochralski method. $\mathrm{Gd}_{x} \mathrm{Y}_{1-x} \mathrm{COB}$ crystals had an uniformity of crystal composition along with growth direction so these crystals confirmed a substitutional solid solution of $\mathrm{Gd}_{x} \mathrm{Y}_{1-x} \mathrm{COB}$. We have succeeded to generate noncritical phase matched THG of $\mathrm{Nd}$ : YAG laser (1064 nm) light in $\mathrm{Gd}_{0.28} \mathrm{Y}_{0.72} \mathrm{COB}$.

\section{Acknowledgements}

This work was supported by the 'Research for the Future' Program of the Japan Society for the Promotion of Science (No. 97R-16101). The authors would like to thank Y Okada, Kogaku Giken Co. Ltd. for polishing the crystals.

\section{References}

Aka $\mathrm{G}$ et al 1996a in OSA TOPS on advanced solid state lasers (eds) S A Payne and C R Pollock (Washington DC: Optical Society of America) Vol. 1

Aka G, Kahn-Harari A, Vivien D, Salin F, Godard J and Benitez J M 1996 Eur. J. Solid State Inorg. Chem. 33727

Chen C, Wu B, Jiang A and You G 1984 Sci. Sin. B7 579

Chen C, Wu Y, Jiang A, Wu B, You G, Li R and Lin S 1989 J. Opt. Soc. Am. B6 616

Iwai M, Kobayashi T, Furuya H, Mori Y and Sasaki T 1997 Jpn J. Appl. Phys. 36276

Kato K 1994 IEEE J. Quantum Electron. 302950

Khamaganova T N, Trunov V K and Dzhurinskii B F 1991 Russian J. Inorg. Chem. 36484

Mori Y, Kuroda I, Nakajima S, Sasaki T and Nakai S 1995a Appl. Phys. Lett. 671818

Mori Y, Kuroda I, Nakajima S, Sasaki T and Nakai S 1995b J. Cryst. Growth 156307

Mori Y, Kuroda I, Nakajima S, Sasaki T and Nakai S 1995c Jpn J. Appl. Phys. 34 L296

Norrestam R, Nygren M and Bovin J-O 1992 Chem. Mater. 4 737

Roberts D A 1992 IEEE J. Quantum Electron. 282057

Sasaki T, Mori Y, Kuroda I, Nakajima S, Yamaguchi $\mathbf{K}$ and Nakai S 1995 Acta Crystallogr. C51 2222

Shannon R D 1976 Acta Crystallogr. A32 751

Stamm U, Zschocke W, Schroder T, Deutsch N and Basting D 1997 Technical Digest of CLEO '97, 11, CFE7

Wu Y, Sasaki T, Nakai S, Yokotani A, Tang $\mathrm{H}$ and Chen $\mathrm{C}$ 1993 Appl. Phys. Lett. 622614

Yap Y K, Inagaki M, Nakajima S, Mori Y and Sasaki T 1996 Opt. Lett. 211348

Yoshimura M, Furuya H, Kobayashi T, Murase K, Yamada I, Mori $\mathrm{Y}$ and Sasaki $\mathrm{T} 1998$ SPIE proc. of third int. conf. on solid state lasers for application to inertial confinement fusion (in print) 